\title{
Differences in feedback- and inhibition-related neural activity in adult ADHD.
}

Citation for published version (APA):

Dibbets, P., Evers, L., Hurks, P. P. M., Marchetta, N., \& Jolles, J. (2009). Differences in feedback- and inhibition-related neural activity in adult ADHD. Brain and Cognition, 70(1), 73-83.

https://doi.org/10.1016/j.bandc.2009.01.001

Document status and date:

Published: 01/01/2009

DOI:

10.1016/j.bandc.2009.01.001

Document Version:

Publisher's PDF, also known as Version of record

Document license:

Taverne

Please check the document version of this publication:

- A submitted manuscript is the version of the article upon submission and before peer-review. There can be important differences between the submitted version and the official published version of record.

People interested in the research are advised to contact the author for the final version of the publication, or visit the DOI to the publisher's website.

- The final author version and the galley proof are versions of the publication after peer review.

- The final published version features the final layout of the paper including the volume, issue and page numbers.

Link to publication

\footnotetext{
General rights rights.

- You may freely distribute the URL identifying the publication in the public portal. please follow below link for the End User Agreement:

www.umlib.nl/taverne-license

Take down policy

If you believe that this document breaches copyright please contact us at:

repository@maastrichtuniversity.nl

providing details and we will investigate your claim.
}

Copyright and moral rights for the publications made accessible in the public portal are retained by the authors and/or other copyright owners and it is a condition of accessing publications that users recognise and abide by the legal requirements associated with these

- Users may download and print one copy of any publication from the public portal for the purpose of private study or research.

- You may not further distribute the material or use it for any profit-making activity or commercial gain

If the publication is distributed under the terms of Article $25 \mathrm{fa}$ of the Dutch Copyright Act, indicated by the "Taverne" license above, 


\title{
Differences in feedback- and inhibition-related neural activity in adult ADHD
}

\author{
Pauline Dibbets *, Lisbeth Evers, Petra Hurks, Natalie Marchetta, Jelle Jolles \\ Maastricht University, Universiteitssingel 50, Clinical Psychological Science, P.O. Box 616, 6200MD, Maastricht, The Netherlands
}

\section{A R T I C L E I N F O}

Article history:

Accepted 7 January 2009

Available online 7 February 2009

\section{Keywords:}

Attention deficit hyperactivity disorder

Functional MRI

Response inhibition

Feedback

Executive control

Adults

Neuroimaging

Go/NoGo

\begin{abstract}
A B S T R A C T
The objective of this study was to examine response inhibition- and feedback-related neural activity in adults with attention deficit hyperactivity disorder (ADHD) using event-related functional MRI. Sixteen male adults with ADHD and 13 healthy/normal controls participated in this study and performed a modified Go/NoGo task. Behaviourally, attention and inhibition problems in the ADHD group were observed; no feedback-related differences between the groups were detected. The neuroimaging data showed that the ADHD group displayed more activation in the inferior frontal gyrus and putamen during response inhibition. During feedback-related processes, the ADHD group displayed less activation in the inferior frontal/orbitofrontal cortex, hippocampus/nucleus accumbens, and caudate nucleus, but more activity in the inferior frontal gyrus. These results indicate that at least two distinguishable underlying brain networks related to response inhibition and feedback are altered in adults with ADHD.
\end{abstract}

(c) 2009 Elsevier Inc. All rights reserved.

\section{Introduction}

Attention-deficit hyperactivity disorder (ADHD) is characterized by attention problems, hyperactivity, and impulsivity (APA, 2000). Especially the third term, impulsivity, has been extensively studied over the past decades. It has been suggested that deficits in impulsiveness can be detected by tasks of inhibitory response control, since one of the most robust findings in ADHD is poor task performance on this type of task, such as the Go/NoGo task, Continuous Performance Test, and the Stop Signal Task (e.g., Gomez, 2003; Willcutt, Doyle, Nigg, Faraone, \& Pennington, 2005). For example, individuals with ADHD, both children as well as adults, have slower response times and make more errors of commission in this respect (Hervey, Epstein, \& Curry, 2004).

Neuroimaging studies have indicated that response inhibition is associated with a neural circuitry involving several areas of the prefrontal cortex (PFC), parietal cortex, the basal ganglia, and the thalamus (see for reviews, Ridderinkhof, van den Wildenberg, Segalowitz, \& Carter, 2004; and Rubia et al., 2001). Both children and adults with ADHD display anatomical and functional abnormalities in this brain circuitry (Schneider, Retz, Coogan, Thome, \& Rosler, 2006). Individuals with ADHD demonstrate, next to behavioral deficits, alterations in brain activation patterns during the performance of a response inhibition task. For example, both hypo- and hyper-activation of the PFC and caudate nucleus have been demonstrated, as well as a recruitment of contralateral frontal areas and

\footnotetext{
* Corresponding author. Fax: +31 (0)43 3884155.

E-mail address: Pauline.Dibbets@dmkep.unimaas.nl (P. Dibbets).
}

additional engagement of parietal areas (see for an overview, Fassbender \& Schweitzer, 2006).

Although some authors suggest that the core symptoms of ADHD are the result of a dysfunction in response inhibition (Barkley, 1997, 2000), others propose that the ADHD symptoms may be the result of altered feedback-related processes, such as a changed sensitivity to reinforcement or omission of an expected reward (Sagvolden, Aase, Johansen, \& Russell, 2005), or incorporate both views (Sergeant, Geurts, Huijbregts, Scheres, \& Oosterlaan, 2003; Sonuga-Barke, 2003). In previous studies on feedback-related processes, ADHD has been associated with aberrant sensitivity to reward, punishment, omission of expected reward, changes in reward schedules, and delay of gratification (see for a review Luman, Oosterlaan, \& Sergeant, 2005). For example, children with ADHD have a strong tendency to prefer an immediate, small reward over a delayed, larger reward (Antrop et al., 2006), and react with a higher level of frustration when an expected reward is omitted (Douglas \& Parry, 1994) than children without ADHD. Furthermore, adults with ADHD symptoms react with a lower emotional response to situations involving punishment (Braaten \& Rosen, 1997).

A number of neuroimaging studies have examined feedback-related processes in healthy adults (e.g., Elliott, Friston, \& Dolan, 2000; Knutson, Adams, Fong, \& Hommer, 2001; van Leijenhorst, Crone, \& Bunge, 2006; Zalla et al., 2000; Zanolie, Van Leijenhorst, Rombouts, \& Crone, 2008). Their findings support the involvement of the dorsal striatum (e.g., caudate nucleus), insula, orbitofrontal cortex (OFC), and dorsolateral prefrontal cortex (dlPFC), and of limbic structures, as the hippocampus, amygdala, ventral striatum (e.g., nucleus accumbens), and the anterior cingulate gyrus. 
To our knowledge only two neuroimaging studies examined altered responses to feedback in individuals with ADHD. As expected, these studies indeed observed alterations in the feedback-related brain areas. In the first fMRI-study, reduced ventral striatal activation, part of the (meso)limbic circuitry, was found in adolescents with ADHD during reward anticipation, relative to healthy controls (Scheres, Milham, Knutson, \& Castellanos, 2007). The second study, a PET-study of Ernst and colleagues (2003) demonstrated that adults with ADHD did not recruit regions as the anterior cingulate cortex and hippocampus during the performance of a reward (feedback)-related decision making task, whereas the healthy controls did. Both structures are a part of the limbic circuitry. A direct comparison between the groups revealed that healthy subjects engaged the hippocampal and insular regions more than did the ADHD subjects. The ADHD group displayed more activity in the caudal part of the anterior cingulate cortex than did the healthy controls.

Although both response inhibition and feedback-related neural activity have been investigated separately in ADHD, no neuroimaging study, to our knowledge, has concurrently examined these processes. The advantage of a simultaneous examination of both processes in one task is the opportunity to further disentangle both processes without using two separate tasks that each might tap on different cognitive processes, resulting in different task-related brain activation patterns. Furthermore, the two before mentioned imaging studies on feedback-related activity in ADHD did not assess brain activity directly related to positive and negative response feedback. In the study of Scheres et al. (2007), specific cues signalled the opportunity to either win money, avoid losing money, or signalled no monetary outcome at all (control trials) on subsequent target responding. Although, the participants did make a substantial number of errors on the target stimulus, the difference in correct and incorrect answers or in gaining and loosing money was not incorporated in the data analysis. In addition, the study of Ernst and colleagues (2003) did not separate decisions followed by positive or negative feedback, but compared activations elicited by both events with a similar control task in which no selection choice was available. To our knowledge, no neuroimaging study has directly examined neurobiological substrates of feedback-related, positive and negative, processing in ADHD.

The main aim of the present study was therefore to investigate brain activation patterns underlying response inhibition and performance feedback in ADHD simultaneously and compare these with the brain activation patterns in normal controls. To this end, a modified Go/NoGo task was used in which participants needed to respond on Go trials, but to inhibit their response on the NoGo trials (see also Evers et al., 2006). In this task, positive feedback indicated correct performance (whether correct inhibition or correct hit), whereas negative feedback indicated incorrect performance (related to incorrect inhibition, omissions, and hits). The advantage of this paradigm is that it enables direct comparisons between neural circuitries involved in response inhibition and circuitries involved in positive and negative feedback. Such comparisons might help to elucidate on the current ADHD models (see for example Barkley, 1997, 2000; Sonuga-Barke, 2003). Based on previous findings on response inhibition tasks, it is expected that, compared to healthy controls, adults with ADHD would have more problems to inhibit their responses, display slower response times, and would show altered brain activation patterns in the executive circuitry, such as the dIPFC, and caudate nucleus (Fassbender \& Schweitzer, 2006). Although ADHD is associated with an altered feedback-related mechanism, behavioral results are not uniform. Some authors report that individuals with ADHD are more sensitive to reward (Douglas \& Parry, 1994), while others note a decreased sensitivity (Haenlein \& Caul, 1987), or do not detect any differences at all (van Meel, Oosterlaan, Heslenfeld, \& Sergeant, 2005). Both the
PET-study of Ernst and colleagues (2003) and the fMRI-study of Scheres et al. (2007) did not report behavioral differences between the ADHD and healthy control group. Therefore, no specific feedback-related differences between the adults with and without ADHD are expected at the behavioral level. However, in line with previous neuroimaging studies, we do expect to find feedback-related activation differences in the limbic structures, such as the anterior cingulate cortex, hippocampus (Ernst et al., 2003), and ventral striatum (Scheres et al., 2007).

\section{Methods and materials}

\subsection{Participants}

A total of 33 participants was recruited for this study, 16 adults with ADHD and 17 education-level matched and age-matched normal controls. The ADHD group consisted of 16 participants with combined attention and hyperactivity problems (ADHD). All participants were male and right-handed. The mean age of the ADHD groups was 28.9 years (SD: 6.44, range 21.9-41.9), and 28.6 years (SD: 6.45, range 21.3-41.3) for the control group. The mean education level (De Bie, 1987) for the ADHD group was 4.88 (SD: 1.59 , range $2-7$ ) and 5.17 (SD: 1.47, range 3-8) for the control group.

\subsubsection{Recruitment and diagnosis}

Control participants were recruited by advertisements in local newspapers. Participants of the ADHD group were recruited by spreading information brochures after group interventions of adults with ADHD and by advertisements on websites of ADHD associations. Only participants in the group intervention that had no other axis I or II diagnosis were approached for participation. Their diagnosis was set by an experienced and specialized ADHDteam including a psychiatrist, a clinical psychologist, a neuropsychologist, and a registered psychiatric nurse. Additionally, each participant received next to the information package a letter emphasizing that only pure ADHD participants were invited to respond. Furthermore, we asked each ADHD participant to hand over a medical or diagnostic report of their specialist or general practitioner. Unfortunately, not all reports were received. Finally, all participants were asked if they had any other disorders beside the diagnosed ADHD. This resulted in the following distribution of co-occurring characteristics: ADHD and depressive symptoms $(n=2)$, ADHD and obsessive/compulsive symptoms $(n=1)$, ADHD and substance abuse (cannabis, $n=1$ ), and ADHD and learning problems $(n=2$, one due to attention problems). Furthermore, one participant received epilepsy medication, one received antihistamine, and one cholesterol medication. Fourteen ADHD participants used methylphenidate-based medication (Ritalin ${ }^{\circledR} n=11$; Concerta ${ }^{\circledR} n=3$ ). None of the control participants reported axis I or II problems. One control participant reported the use of antiasthma medication (Seritide discus).

Exclusion criteria for all participants were presence of any current axis 1 psychiatric diagnosis other than ADHD, IQ < 80, neurological trauma or disorder, and contraindication for MRI. On suspicion of ADHD-problems in the control participants during testing, the Current Symptoms Scale and Childhood Symptoms Scale was administered to all participants (see description Questionnaire and Neuropsychological Test below). This checklist enabled verification of the presence of ADHD-problems in the ADHD group and the absence of these problems in the control group. Inclusion criteria for the ADHD group were a minimum score of six symptoms on at least one of the current symptoms subscales and retrospective childhood subscales (Barkley \& Murphy, 1998). Inclusion criteria for the control group were a maximum of two symptoms and on each of the current symptoms scales and a maximum of three symptoms on each of the retro- 
spective childhood subscales (mean norm scores Barkley \& Murphy, 1998).

The study was carried out in accordance with the declaration of Helsinki and was started after approval of the local Medical Ethical Committee (Maastricht, the Netherlands, No: 05.045.4). Before onset of the study, all participants provided a written informed consent. Each participant was paid 50 Euros and received a compact disk with their anatomical brain scan.

\subsection{Questionnaire and neuropsychological test}

\subsubsection{The Current Symptoms Scale and Childhood Symptoms Scale}

The Current Symptoms Scale and Childhood Symptoms Scale was a short, self-report screening questionnaire to measure ADHD in adults. The questions are based on the ADHD symptom list of the DSM-IV (normative data are published in Barkley \& Murphy, 1998). The questionnaire contains a list concerning current symptoms of ADHD and a retrospective list concerning symptoms during childhood. For the present study, participants with ADHD were provided with two copies of the current symptoms list, one copy to fill in judging their behavior while using ADHD medication, one copy for judging their behavior during a medication free period. The control participants received only one current symptoms list. Additionally, all participants received one retrospective list containing items related to childhood behavior. Each list contains nine items measuring inattention and nine items measuring hyperactivity (6)/impulsivity problems (3). Each item can be scored on a 4point-scale ranging from 'never (1)' to 'very often (4)' A score is considered as a symptom if an item is answered with often or very often, leading to a maximum of nine symptoms for inattention and/or nine symptoms for hyperactivity/impulsivity (Barkley \& Murphy, 1998).

\subsubsection{The WAIS-R Block Design (Uterwijk, 2000)}

The subtest Block Design of the WAIS-R measures visuospatial abilities and is frequently used as an estimation of general intelligence (Kaufman \& Lichtenberger, 1999). Furthermore, if matched for level of education, no difference in performance on the WAIS$\mathrm{R}$ Block Design between adults with ADHD and normal control is expected (Bridgett \& Walker, 2006; Seidman, Biederman, Weber, Hatch, \& Faraone, 1998). Therefore, in the present study, where groups are matched for level of education, WAIS-R Block Design can be used to check for similar levels of general intelligence in each group, or in case a difference is observed between the groups, it can function as a covariate in the data analyses.

\subsection{Functional MRI test}

The present study used the Go/NoGo task as described by Evers et al. (2006) (see Fig. 1). This task is based on the Go/NoGo task of Garavan, Ross, and Stein (1999) and was programmed in E-prime V1.0 (Psychology Software Tools, http://www.pstnet.com/). During this task a stream of yellow letters was presented against a black background. The letters $X$ and $Y$ was presented serially mixed with other letters (fillers). The task of the participant was to press a button on alternating presentations of $\mathrm{X}$ and $\mathrm{Y}$, that is $\mathrm{X}$ preceded by $\mathrm{Y}$ or $Y$ preceded by $X$ (Go trials), and to refrain from responding by repetition of $\mathrm{X}$ or $\mathrm{Y}$, that is $\mathrm{X}$ preceded by $\mathrm{X}$ or $\mathrm{Y}$ preceded by $\mathrm{Y}$ (NoGo trials). No responses were required on the filler trials. Correct responses on the Go trials and correct inhibition of responses on the NoGo trials were followed by a green ${ }^{1}$ square (positive feedback). No positive feedback was provided after correctly omitted

\footnotetext{
${ }^{1}$ For interpretation of color in Fig. 1, the reader is referred to the web version of this article.
}

filler trials. A red square, negative feedback, was presented after responses to NoGo trials, responses to letters other than $\mathrm{X}$ and $\mathrm{Y}$, omission of a response on Go trials, and to responses after the offset of the stimulus. This time limit was set to encourage fast responding and to complicate the inhibition of a response. The timing of the events can be found in the legend of Fig. 1. A Go trial was presented every $4 \mathrm{~s}$ on average, a NoGo trial every $25 \mathrm{~s}$ on average. A total of 1000 stimuli was presented containing 150 Go trials and 25 NoGo trials. The stimuli were divided into two blocks of each 500 stimuli. Each block started with a passive resting state (17 TRs) in which no response was required. Participants were instructed to start responding on the first X or Y presentation (Go trial) after this resting state. During the experimental task, both response time (RT) and response accuracy were measured on each trial. Two weeks prior to scanning, the task was trained in a simulation scanner. The training started with 400 stimuli with 120 Go trials and no NoGo trials. During the second part of the training, 350 stimuli were presented of which 55 were Go trials and seven were NoGo trials. All task properties of the training were otherwise identical to that of the scan task.

\subsection{MRI scanning}

The participants were scanned using a 1.5T MRI whole body scanner (Philips Gyroscan ACS-NT, Eindhoven, The Netherlands) with a synergy head coil. Head fixation was accomplished by using foam padding. Each scan session started with a sagittal T1weighted anatomical image (150 slices, imaging matrix $=256 \times 256$, slice thickness $1 \mathrm{~mm}$, no gap). Functional images were based on a $\mathrm{T} 2 *$ weighted gradient echo sequence with the following parameters: number of slices $=24$, flip angle $=90^{\circ}$, $\mathrm{TE}=27 \mathrm{~ms}, \mathrm{TR}=1750 \mathrm{~ms}$, field of view $=224 \times 120 \times 224$, imaging matrix $=64 \times 64$, slice thickness $=5 \mathrm{~mm}$, slice gap $=0 \mathrm{~mm}$. Scanning orientation was axial and slice order was ascending. During each block, 195 images for all slices were collected resulting in a total of 390 images.

\subsection{Procedure}

The experiment was conducted in two 2-h sessions, about two weeks apart. In session one the Go/NoGo task was practiced in a simulation scanner and the subtest WAIS-R Block Design was administered. Participants with ADHD were requested to refrain from any ADHD medication at least $24 \mathrm{~h}$ prior to the second session during which anatomical and functional scans were made. After completion of the entire experiment all participants were asked to fill in the Current Symptoms Scale(s) and Childhood Symptoms Scale.

\subsection{Behavioral data analysis}

The WAIS-R Block Design data were transformed to standard $t$ scores (standardized mean: 50, SD: 10 ). A paired $t$-test was used to detect a possible decline in ADHD symptoms through use of ADHD medication. Dependent measures of the Go/NoGo task were the percentage of correct Go trials, the percentage of correct NoGo trials (no response), and the error percentage. The latter was subdivided in omitted Go trials, responses on NoGo trials, and responses on other letters than $\mathrm{X}$ or $\mathrm{Y}$ (fillers). The first type of errors, omitted Go trials, is considered to measure inattention, whereas the second type of errors, responses on NoGo trials, is thought to reflect hyperactivity/impulsivity (Hervey et al., 2004). The mean response times (RTs) of the following trial types were calculated: RT of a correct Go trial preceded by a correct Go trial (baseline $\mathrm{RT}, \mathrm{RT}_{\mathrm{bl}}$ ) as a measure for general responding speed, the RT on a correct Go trial after an omitted Go trial (omission 


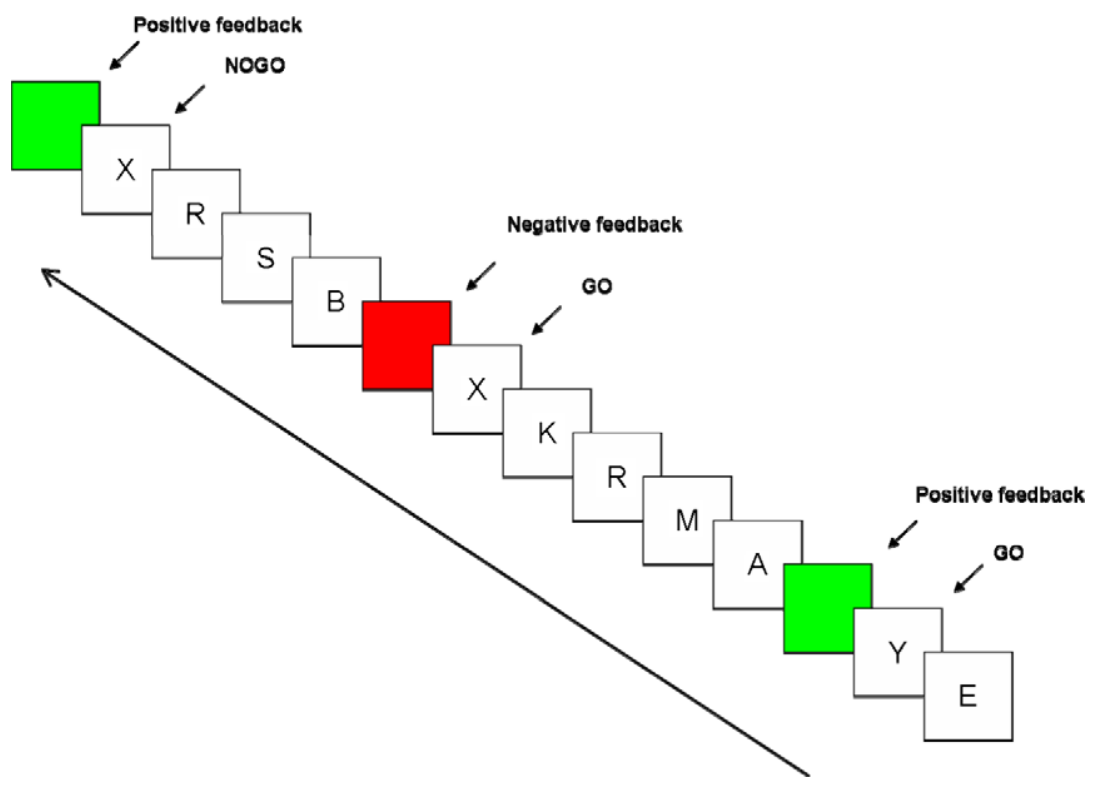

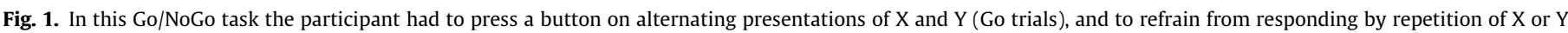

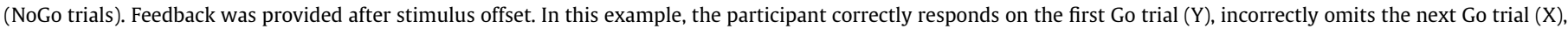

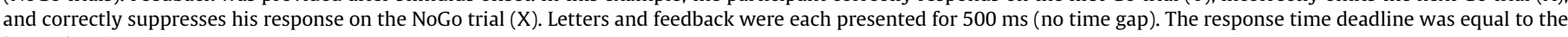
letter duration.

$\mathrm{RT}, \mathrm{RT}_{\mathrm{om}}$ ), and the RT on a correct Go trial after an uninhibited, incorrect, NoGo trial (inhibition failure $\mathrm{RT}, \mathrm{RT}_{\text {if }}$ ). Note that the RTs on these trial combinations are almost always interspersed with filler trials (see also Fig. 1). The reason for this subdivision in RT data is that this enables us to examine possible group differences regarding behavioral adaptations after negative feedback. These adaptations might consist of faster responding on a Go trial after an omitted Go trial and/or slowing down after an uninhibited, incorrect, NoGo trial.

The accuracy data of the Go/NoGo task were analyzed using analyses of variance, ANOVA (SPSS, version 13.0 for Windows). In each analysis group, ADHD and control group, functioned as factor and the several outcome measures functioned as dependent variables. The RT data were analyzed using a General Linear Model (GLM) repeated measures, with RTs as within subjects factor and group as between subjects factor. A simple contrast with $\mathrm{RT}_{\mathrm{bl}}$ as reference category was carried out to detect possible RT changes after making an error.

Furthermore, a bivariate correlation (Spearman's $\rho$ ) was calculated between the percentage omitted Go trials and the inattention score on the Current Symptoms Scale (no medication). Similarly, a bivariate correlation (Spearman's $\rho$ ) was calculated between the percentage uninhibited NoGo trials and hyperactivity/impulsivity score. The rejection criterion was set at $p<.05$.

\subsection{Image analysis}

SPM2 (Wellcome Department of Cognitive Neurology, London, UK) was used for data processing. Preprocessing procedures included slice acquisition time correction (slice 12 as a reference slice; TA $=1.68$ ) and within subject realignment (Realign and Unwarp) using the first reference slice as a reference. Images were spatially normalized to the EPI template based in the Montreal Neurological Institute (MNI) reference brain. Thereafter, the images were spatially smoothed using a Gaussian $(8 \mathrm{~mm}$ fullwidth at half maximum) kernel and high passed filtered to a maximum of $1 / 128 \mathrm{~Hz}$.

A canonical hemodynamic response function (HRF) was used as a covariate in a GLM and a parametric estimate was generated for each voxel for each stimulus type. Trials were subdivided in the following stimulus types: correct Go trials, correct NoGo trials, positive feedback trials (feedback after correct Go and correct NoGo trials), and negative feedback trials (feedback after incorrect Go and incorrect NoGo trials). Negative feedback after errors on filler trials was not included in the GLM. Not only did this sort of error rarely occur, the type of error also differs from the type of errors on Go and NoGo trials.

Individual contrast images were taken to a second level analysis, in which $t$-values were calculated for each voxel treating inter-subject variability as a random effect. The hemodynamic response function was modeled to the onset of the stimulus for the correct Go and the correct NoGo trials, and modeled to the onset of the feedback for positive and negative feedback trials.

The following task-related contrasts were calculated. Firstly, to assess brain activation associated with response inhibition, correct NoGo trials were compared with correct Go trials (contrast 1). Secondly, to assess brain activation related to negative feedback, negative feedback was compared to positive feedback (contrast 2). These task-related contrasts were calculated for all data (two groups together).

The following between-group comparisons (ADHD $>$ Controls and Controls > ADHD) were made. Firstly, brain activation associated with response inhibition (correct NoGo trials compared to correct Go trials) was compared between groups (contrast 3). Secondly, brain activation associated with correct NoGo trials was compared between groups (contrast 4 ) and brain activation associated with correct Go trials was compared between groups (contrast 5). Thirdly, brain activation associated with negative feedback (negative feedback compared to positive feedback) was compared between groups (contrast 6). Fourthly, brain activation associated with positive feedback was compared between groups (contrast 7) and brain activation associated with negative feedback was compared between groups (contrast 8). Finally, we compared overall activation (all events together) between groups as a control condition (contrast 9). In this way we could ensure that differences in brain activation during specific cognitive sub processes between the groups were not due to differences in overall brain activation. 
The following analyses were carried out for the between-group comparisons. Contrasts 3, 4, and 5 were first analyzed with a whole brain analysis, and thereafter the bilateral inferior frontal gyrus (including the orbitofrontal cortex), the anterior cingulate cortex (ACC), the striatum, and the hippocampus were used as regions of interest (ROI) in ROI analyses (Bush, Valera, \& Seidman, 2005; Durston, 2003; Sonuga-Barke, 2003). Contrasts 6, 7, 8, and 9 were first analyzed with a whole brain analysis and thereafter the ACC, orbitofrontal cortex, striatum, hippocampus, and the amygdala were used as an ROI in ROI analyses (see for example, Bush et al., 2005; Fassbender \& Schweitzer, 2006; Sonuga-Barke, 2003).

Based on previous studies, we hypothesize that the AHDH group will show reduced activation in the dorsal ACC (Bush et al., 1999; Tamm, Menon, Ringel, \& Reiss, 2004), the striatum (Vaidya et al., 1998), and the hippocampus (Schulz et al., 2004). Based on the finding that ADHD is related to higher frontal activation on a Go/NoGo task (Vaidya et al., 1998), we hypothesized that activation in the inferior frontal cortex is increased in the ADHD group. Braaten and Rosen (1997) showed that adults with ADHD react with a lower emotional response to situations involving punishment. Based on this finding, we hypothesize reduced activation of the amygdala during negative feedback in the ADHD group.

For ROI analyses the WFU PickAtlas (tool versions 2.0) was used which is available as a tool within SPM2. The ACC, the orbitofrontal cortex (bilateral superior, bilateral middle and bilateral inferior orbitofrontal together as one ROI), the striatum (bilateral caudate and bilateral putamen as separate ROIs), the hippocampus (bilateral) en the amygdala (bilateral) were chosen as AAL region (automated anatomical labelling, Tzourio-Mazoyer et al., 2002) within the PickAtlas. For the nucleus accumbens the TAL coordinates $[4,10,-5]$ and $[-4,10,-5]$ (based on the Talairach Atlas) were used as center coordinate of a $10 \mathrm{~mm}$ sphere. For all analyses, results are reported when $P_{\text {cluster_corrected }}<0.05$. Task-related activation is reported when clusters are larger than 50 voxels, differences in brain activation between groups are reported when clusters contain three voxels or more. For anatomical labelling and report, the center MNI coordinates of the significant clusters were converted to TAL coordinates (http:// eeg.sourceforge.net/doc_m2html/bioelectromagnetism/mni2tal. html). The Talairach Client (http://www.talairach.org/index.html) was used for anatomical labeling. Labeling was checked and if necessary adjusted by using the Talairach atlas (Talairach \& Tournoux, 1988).

\section{Results}

\subsection{Demographic and neuropsychological data}

A total of four participants was excluded. Three participants of the control group displayed too many ADHD symptoms (all five or more symptoms on the current or childhood scale). Finally, one control participant was excluded because no responses were recorded due to equipment failure during both blocks of the scan version of the Go/NoGo task. Table 1 summarizes the demographic and neuropsychological data of the remaining 29 participants. The two groups did not significantly differ with regard to age and education level, $F s(1,29)<1.79$, $p s>.19$. Furthermore, no group differences were observed on the included estimator of general intelligence, the WAIS-R Block Design, $F<1$. As expected, the ADHD group displayed more inattentive and hyperactivity/impulsivity symptoms on the Current Symptoms Scale(s) and Childhood Symptoms Scale, $F s(1,28)>26.09$, $p s<.001$. The use of ADHD medication did reduce both inattentive and hyperactivity/impulsivity symptoms $t \mathrm{~s}(15)>4.51$, ps $<.001$.
Table 1

Demographic and neuropsychological data of included participants.

\begin{tabular}{|c|c|c|c|c|}
\hline & \multicolumn{2}{|c|}{$\operatorname{ADHD}(n=16)$} & \multicolumn{2}{|c|}{ Control group $(n=13)$} \\
\hline & Mean & SD & Mean & SD \\
\hline Age & 28.9 & 6.5 & 28.1 & 5.9 \\
\hline Education level & 4.9 & 1.7 & 5.7 & 1.3 \\
\hline WAIS-R Block Design $t$-score & 65.3 & 7.3 & 66.7 & 8.5 \\
\hline \multicolumn{5}{|l|}{ Current symptoms } \\
\hline No medication inattention & $6.1^{*}$ & 2.7 & $0.4^{*}$ & 1.4 \\
\hline No medication hyper. & $5.9^{*}$ & 2.6 & $1.2^{*}$ & 2.4 \\
\hline Medication inattention & 1.2 & 1.4 & - & - \\
\hline Medication hyper. & 1.9 & 2.1 & - & - \\
\hline \multicolumn{5}{|l|}{ Childhood symptoms } \\
\hline Inattention & $6.1^{*}$ & 3.1 & $0.7^{*}$ & 1.1 \\
\hline Hyper. & $5.9^{*}$ & 2.6 & $0.6^{*}$ & 1.8 \\
\hline
\end{tabular}

Note: Current symptoms is the current symptoms scale; childhood symptoms is the childhood symptoms scale; hyper. is hyperactivity/impulsivity.

Is a significant difference between the ADHD and control group, $p<.05$.

\subsection{The Go/NoGo task}

\subsubsection{Accuracy}

Table 2 summarizes the accuracy data in percentages and RTs for the Go/NoGo task. The ANOVA revealed that the ADHD group omitted significantly more Go trials than did the control group, resulting in a higher omission percentage and a lower percentage of correct Go trials, $F(1,28)=5.80, p<.05$. These results reflect larger inattention problems in the ADHD than in the control group. The difference in percentage of inhibition failures on the NoGo trials just failed to reach significance, $F(1,28)=3.64, p=.07$. Although only a trend was observed, the direction of this effect indicated that the ADHD group experienced more inhibition problems than did the control group. The percentage of responses on filler stimuli was low $(<1 \%)$ and no difference between the two groups was observed, $F(1,28)=2.54, p=.12$. These results are in line with previous research on response inhibition tasks in adults with ADHD (see for an overview Hervey et al., 2004).

\subsubsection{Response times (RTs)}

The GLM repeated measures revealed that after omitted Go trials, $\mathrm{RT}_{\text {om, }}$, participants responded faster compared to baseline responses, $\mathrm{RT}_{\mathrm{bl}}, F(1,27)=8.67, p<.001$, but no alteration in speed of responding was observed after inhibition failures, $\mathrm{RT}_{\mathrm{if}}, F<1$. The analysis also revealed a main effect of group, $F(1,27)=5.10$, $p<.05$, with a general slower responding for the ADHD group. No

Table 2

Behavioral data for the Go/NoGo task: means with standard deviations.

\begin{tabular}{lccccc}
\hline & \multicolumn{2}{l}{ ADHD $(n=15)$} & & \multicolumn{2}{c}{ Control group $(n=13)$} \\
\cline { 2 - 3 } & Mean & SD & & Mean & SD \\
\hline Accuracy & & & & & \\
Correct Go trials & $87.3^{*}$ & 8.5 & & $93.8^{*}$ & 5.5 \\
Omitted Go trials & $12.7^{*}$ & 8.5 & & $6.2^{*}$ & 5.5 \\
Incorrect NoGo trials & $29.3^{\#}$ & 15.0 & & $19.1^{\#}$ & 13.3 \\
Filler responses & .44 & .36 & & .26 & .25 \\
$R T^{* *}$ & & & & & \\
$\mathrm{RT}_{\text {bl }}$ & 390 & 18.0 & & 378 & 22.3 \\
$\mathrm{RT}_{\text {om }}$ & 384 & 20.9 & & 364 & 23.5 \\
$\mathrm{RT}_{\text {if }}$ & 394 & 34.2 & & 373 & 27.8 \\
\hline
\end{tabular}

Note: Accuracy data are presented in percentages, RT is mean response time in milliseconds, $\mathrm{RT}_{\mathrm{bl}}$ is baseline RT, $\mathrm{RT}_{\text {om }}$ is $\mathrm{RT}$ after an omitted Go trial, $\mathrm{RT}_{\text {if }}$ is $\mathrm{RT}$ after a NoGo inhibition failure.

* Is a significant difference between the ADHD and control group.

** Is RTs ADHD > control, $p<.05$.

\# $p=.07$. 
Table 3

Task-related activation assessed by whole brain analysis. Data from the ADHD and control group $(n=29)$ taken together.

\begin{tabular}{|c|c|c|c|c|c|}
\hline TAL & $\begin{array}{l}\text { Cluster } \\
\text { size }\end{array}$ & $\begin{array}{l}T- \\
\text { value }\end{array}$ & $P_{\text {corrected_cluster }}$ & Brain region & BA \\
\hline \multicolumn{6}{|c|}{ NoGo-Go (contrast 1 ) } \\
\hline$[61,-42,6]$ & 1049 & 7.53 & 0.000 & $\begin{array}{l}\text { Superior temporal } \\
\text { gyrus }\end{array}$ & 22 \\
\hline$[50,-51,32]$ & & 5.24 & & Supramarginal gyrus & 40 \\
\hline$[57,-45,32]$ & & 5.10 & & & \\
\hline$[46,34,19]$ & 3263 & 7.20 & 0.000 & Middle frontal gyrus & 46 \\
\hline$[53,12,12]$ & & 6.47 & & Inferior frontal gyrus & 44 \\
\hline$[53,18,19]$ & & 6.26 & & & 45 \\
\hline$[-63,-33,37]$ & 1370 & 6.90 & 0.000 & $\begin{array}{l}\text { Inferior parietal } \\
\text { lobule }\end{array}$ & 40 \\
\hline$[-40,-52,49]$ & & 5.31 & & & \\
\hline$[-28,-69,57]$ & & 5.88 & & $\begin{array}{l}\text { Superior parietal } \\
\text { lobule }\end{array}$ & 7 \\
\hline$[26,-71,51]$ & 788 & 6.35 & 0.000 & Precuneus & 7 \\
\hline$[44,-52,54]$ & & 5.47 & & $\begin{array}{l}\text { Inferior parietal } \\
\text { lobule }\end{array}$ & 40 \\
\hline$[50,-48,50]$ & & 4.64 & & & \\
\hline$[6,33,43]$ & 298 & 5.60 & 0.002 & $\begin{array}{l}\text { Superior frontal } \\
\text { gyrus }\end{array}$ & 8 \\
\hline$[14,37,48]$ & & 4.34 & & & \\
\hline$[-34,21,-3]$ & 448 & 5.05 & 0.000 & Inferior frontal gyrus & 47 \\
\hline$[-46,20,21]$ & & 4.48 & & Middle frontal gyrus & 46 \\
\hline$[-46,32,17]$ & & 4.45 & & & \\
\hline$[18,11,64]$ & 310 & 5.51 & 0.000 & $\begin{array}{l}\text { Superior frontal } \\
\text { gyrus }\end{array}$ & 6 \\
\hline$[16,-2,68]$ & & 4.33 & & & \\
\hline$[10,21,62]$ & & 3.86 & & & \\
\hline$[-32,3,55]$ & 269 & 4.59 & 0.004 & Middle frontal gyrus & 6 \\
\hline$[-50,4,40]$ & & 4.28 & & & \\
\hline$[-44,-1,48]$ & & 4.56 & & Precentral gyrus & 6 \\
\hline \multicolumn{6}{|c|}{ Negative-positive feedback (contrast 2) } \\
\hline$[-46,-26,57]$ & 3815 & 8.92 & 0.000 & Postcentral gyrus & 2 \\
\hline$[-53,-23,47]$ & & 7.95 & & & \\
\hline$[-57,-39,41]$ & & 7.10 & & $\begin{array}{l}\text { Inferior parietal } \\
\text { lobule }\end{array}$ & 40 \\
\hline$[53,21,-9]$ & 4389 & 8.58 & 0.000 & Inferior frontal gyrus & 47 \\
\hline$[57,17,-4]$ & & 7.45 & & & \\
\hline$[50,41,9]$ & & 7.26 & & Middle frontal gyrus & 46 \\
\hline$[46,-60,51]$ & 2724 & 7.06 & 0.000 & $\begin{array}{l}\text { Superior parietal } \\
\text { lobule }\end{array}$ & 7 \\
\hline$[59,-37,39]$ & & 5.42 & & $\begin{array}{l}\text { Inferior parietal } \\
\text { lobule }\end{array}$ & 40 \\
\hline$[61,-48,4]$ & & 5.27 & & $\begin{array}{l}\text { Middle temporal } \\
\text { gyrus }\end{array}$ & 22 \\
\hline$[-51,12,5]$ & 497 & 6.16 & 0.000 & Precentral gyrus & 44 \\
\hline$[-48,11,-14]$ & & 5.00 & & $\begin{array}{l}\text { Superior temporal } \\
\text { gyrus }\end{array}$ & 38 \\
\hline$[-4,-24,-17]$ & 353 & 5.24 & 0.002 & Midbrain & \\
\hline$[8,-24,-14]$ & & 4.25 & & Substantia nigra & \\
\hline
\end{tabular}

group x RT interactions were observed $F s(1,27)<1.07, p s>.31$. These results indicate that after inattention, that is an omitted Go trial, participants adjusted their performance on the next upcoming Go trial. As a result faster responses were observed on these Go trials $\left(\mathrm{RT}_{\mathrm{om}}\right)$. This speeding up effect was observed for both groups and did not differ between the control and ADHD group, indicating no observable group differences in sensitivity to feedback. The general slower responses observed in the ADHD group are thought to reflect attention problems or slower information processing- or motor-speed associated with high (executive) task demands (Hervey et al., 2004).

\subsubsection{Correlations}

Spearman's $\rho$ bivariate correlations revealed a significant relation between the percentage of omitted responses and the inattention score of the Current Symptoms Scale, $\rho=.514, p<.05$, indicating that a higher level of inattention coincided with more omission errors. No significant relation was observed between the percentage of uninhibited Go's and impulsivity/hyperactivity scores of the Current Symptoms Scale, $\rho=.337, p=.11$.

\subsection{Imaging}

\subsubsection{Task-related activity}

Brain activations related to response inhibition (NoGo-Go, contrast 1 ) and negative compared to positive feedback (contrast 2) are shown in Table 3. Large activation clusters related to response inhibition were found in the superior temporal/supramarginal gyrus, middle/inferior frontal gyrus (bilateral), superior frontal gyrus, and the inferior/superior parietal lobe (bilateral). Brain activation during negative compared to positive feedback was found in large activation clusters in the postcentral/inferior parietal gyrus, the inferior/middle frontal gyrus, the superior/inferior parietal, precentral/superior temporal gyrus, and the midbrain.

\subsubsection{Group differences}

Differences in brain activation between the ADHD and the control group are shown in Table 4. The NoGo-Go contrast (contrast 3) did not reveal any group differences. During NoGo trials the ADHD group tended $\left(P_{\text {corrected_cluster }}=0.09\right)$ to show more activation in the putamen than the control group (contrast 4). However, when we use the often applied threshold of $P_{\text {uncorrected voxel }}<0.001$ (for example, Cao et al., 2008; Konrad, Neufang, Hanisch, Fink, \& Herpertz-Dahlmann, 2006), the putamen activation significantly differed ( $P_{\text {uncorrected_voxel }}=0.000$ ) between the groups. Furthermore, the ADHD group tended to show more activation $\left(P_{\text {uncorrected_voxel }}=0.000\right)$ in the left inferior frontal gyrus during NoGo trials than did the control group. During Go trials, this brain area also tended $\left(P_{\text {corrected_cluster }}=0.07 ; P_{\text {uncorrected_voxel }}=0.000\right)$ to be more activated in the ADHD group than in the controls group during Go trials (contrast 5). Significant more activation in the ADHD group during Go trials was observed in the right middle frontal gyrus.

The negative-positive feedback contrast (contrast 6 ) revealed that, compared to the control group, the ADHD group displayed significant more activity in the left inferior frontal gyrus. During positive feedback controls showed more bilateral activation in the inferior frontal gyrus/orbitofrontal cortex than did the ADHD group (contrast 7 , see Fig. 2 ). Furthermore, a trend $\left(P_{\text {corrected_cluster }}=\right.$ $0.11 ; P_{\text {uncorrected_voxel }}<0.001$ ) towards more activity in the caudate nucleus was observed in the control group during positive feedback. During negative feedback the controls showed more activation in the hippocampus/nucleus accumbens (contrast 8, see Fig. 3). Furthermore, the ADHD showed more activation during the Go/NoGo task in general (all events together) in the right middle frontal gyrus (contrast 9). No other differences were found.

In addition to these between-group differences, we assessed the correlation between response inhibition performance (total number of errors of uninhibited NoGo trials on both blocks) and brain activation during response inhibition (NoGo-Go). The left and right inferior frontal cortex correlated positively with the number of response inhibition errors (see Table 5 and Fig. 4).

\section{Discussion}

The main aim of the present study was to simultaneously examine brain activation patterns underlying response inhibition and performance feedback in adults with ADHD. To this end, a modified Go/NoGo task was used in which correct responses were followed by positive feedback and incorrect responses were signified by negative feedback (see also Evers et al., 2006). The behavioral results indicated that both adults with and without ADHD speeded up responding on Go trials after a previously omitted Go trial. Furthermore, adults with ADHD omitted more Go trials and were, in 
Table 4

Differences in brain activation during the Go/NoGo task between the ADHD and the control group.

\begin{tabular}{|c|c|c|c|c|c|}
\hline TAL & $\begin{array}{l}\text { Cluster } \\
\text { size }\end{array}$ & $\begin{array}{l}T \text { - } \\
\text { value }\end{array}$ & $P$-value & Brain region & BA \\
\hline \multicolumn{6}{|l|}{ NoGo (contrast 4) } \\
\hline$[26,-2,6]^{\mathrm{a}}$ & 7 & 3.78 & $\begin{array}{l}P_{\text {corrected_cluster }}=0.09 \\
P_{\text {uncorrected_voxel }}=0.000\end{array}$ & Putamen & \\
\hline$[-50,36,-12]^{a}$ & 46 & 4.32 & $\begin{array}{l}P_{\text {corrected_cluster }}=0.08 \\
P_{\text {uncorrected_voxel }}=0.000\end{array}$ & $\begin{array}{l}\text { Inferior frontal } \\
\text { gyrus }\end{array}$ & 47 \\
\hline \multicolumn{6}{|l|}{ Go (contrast 5) } \\
\hline$[44,38,-14]^{\mathrm{a}}$ & 59 & 4.21 & $\begin{array}{l}P_{\text {corrected_cluster }}=0.05 \\
P_{\text {uncorrected_voxel }}=0.000 \\
\text { see above }\end{array}$ & $\begin{array}{l}\text { Middle frontal } \\
\text { gyrus }\end{array}$ & 11 \\
\hline$[-50,34,-12]^{a}$ & 50 & 4.59 & $\begin{array}{l}P_{\text {corrected_cluster }}=0.07 \\
P_{\text {uncorrected_voxel }}=0.000\end{array}$ & $\begin{array}{l}\text { Inferior frontal } \\
\text { gyrus }\end{array}$ & 47 \\
\hline \multicolumn{6}{|c|}{$\begin{array}{l}\text { Negative-positive feedback (contrast } 6 \text { ) } \\
\text { ADHD > controls }\end{array}$} \\
\hline$[-50,34,-12]^{\mathrm{a}}$ & 18 & 3.94 & $\begin{array}{l}P_{\text {corrected_cluster }}=0.15 \\
P_{\text {uncorrected_voxel }}=0.000\end{array}$ & $\begin{array}{l}\text { Inferior frontal } \\
\text { gyrus }\end{array}$ & 47 \\
\hline \multicolumn{6}{|c|}{ Positive feedback (contrast 7) } \\
\hline $\begin{array}{l}\text { Controls }>\text { ADHD } \\
{[-48,36,-12]^{a}}\end{array}$ & 61 & 4.65 & $P_{\text {corrected_cluster }}=0.04$ & $\begin{array}{l}\text { Inferior frontal } \\
\text { gyrus/ } \\
\text { orbitofrontal } \\
\text { cortex }\end{array}$ & 47 \\
\hline$[42,38,-14]^{\mathrm{a}}$ & 64 & 4.33 & $P_{\text {corrected_cluster }}=0.03$ & $\begin{array}{l}\text { Middle frontal } \\
\text { gyrus/ } \\
\text { orbitofrontal } \\
\text { cortex }\end{array}$ & 11 \\
\hline$[-20,-11,21]^{\mathrm{a}}$ & 4 & 3.52 & $\begin{array}{l}P_{\text {corrected_cluster }}=0.11 \\
P_{\text {uncorrected_voxel }}=0.001\end{array}$ & Caudate nucleus & \\
\hline \multicolumn{6}{|c|}{ Negative feedback (contrast 8) } \\
\hline$[26,-9,-20]^{\mathrm{a}}$ & 23 & 4.70 & $P_{\text {corrected_cluster }}=0.05$ & $\begin{array}{l}\text { Hippocampus/ } \\
\text { nucleus } \\
\text { accumbens }\end{array}$ & \\
\hline \multicolumn{6}{|c|}{ Overall activation (contrast 9) } \\
\hline$[38,23,38]$ & 182 & 5.55 & $P_{\text {corrected_cluster }}=0.05$ & $\begin{array}{l}\text { Middle frontal } \\
\text { gyrus }\end{array}$ & 9 \\
\hline
\end{tabular}

${ }^{\mathrm{a}}$ Region of interest (ROI) analysis.

general, slower than the control group. The number of response inhibition failures, observed in responses on NoGo trials, were larger in the ADHD group than in the control group, however this difference just failed to reach significance $(p=.07)$. Finally, more omitted Go trials coincided with higher inattention scores on the Current Symptoms Scale and Childhood Symptoms Scale. Taken together, the behavioral data indicate that in both groups negative feedback after an omitted Go response resulted in faster, adjusted responding on subsequent Go trials. No differential effect of this feedback on RTs was observed between the two groups, providing no behavioral evidence for a changed sensitivity towards (negative) feedback in the ADHD group. The attention problems of the ADHD group were found in terms of more omitted Go trials and slower response times, whereas the inhibition problems were marked by a tendency of more responses on the NoGo trials. Finally, a correlation between the number of omitted Go responses and inattention score was observed, indicating a relation between both measures. These observed behavioral attention and inhibition problems in adults with ADHD concord with other, similar studies (see for a meta-analysis Hervey et al., 2004).
Task-related brain activation associated with response inhibition on NoGo trials versus Go trials was observed in large activation clusters in the right superior temporal/supramarginal gyrus, middle/inferior frontal gyrus (bilateral), superior frontal, and the superior/inferior parietal lobule (bilateral). Activation related to negative feedback (negative-positive feedback) was observed in large activation clusters in the left postcentral/inferior parietal gyrus, the right inferior/middle frontal gyrus, the right superior/ inferior parietal lobule, the left precentral/superior temporal gyrus, and the left midbrain. These results largely correspond with previous neuroimaging studies examining response inhibition (Evers et al., 2006; see for an overview, Ridderinkhof, van den Wildenberg, et al., 2004; Rubia et al., 2001; and Simmonds, Pekar, \& Mostofsky, 2008) and partially correspond to feedback-related activity in healthy participants (Chevrier, Noseworthy, \& Schachar, 2007; Stevens, Kiehl, Pearlson, \& Calhoun, 2007; van Leijenhorst et al., 2006; Zanolie et al., 2008).

Differences between the ADHD and control group regarding response inhibition were only observed while analyzing NoGo and Go trials separately. Compared to the control group, the ADHD group recruited additional brain regions during the performance of the Go/NoGo task. Nearly significant increases were observed in the right putamen and left inferior frontal gyrus during the NoGo trials and marginally significant increases were observed in the right middle and left inferior frontal gyrus during Go trials (all $P_{\text {uncorrected_voxel }}<0.001$ ). Although we did expect to find decreased rather than increased activity, these results are not uncommon. Fassbender and Schweitzer (2006) suggest that children and adults with ADHD engage alternative, compensatory brain regions and use different strategies in order to optimally perform cognitive tasks. In their review they report that several studies indeed observe additional prefrontal activity in ADHD groups during the performance of a Go/NoGo task. They also report enhanced putamen activity in adults with ADHD during the performance of a complex cognitive task.

Feedback-related group differences (negative-positive feedback) were only observed in the left inferior frontal gyrus, with the ADHD group displaying more activity than the control group $\left(P_{\text {uncorrected_voxel }}<0.001\right)$. Separate group analyses of the positive and negative feedback revealed that during positive feedback the control group engaged the left and right orbitofrontal cortex more strongly and displayed more activity in the left caudate nucleus $\left(P_{\text {uncorrected voxel }}<0.001\right)$. During negative feedback the control group displayed more right hippocampal/nucleus accumbens activation. These data partly correspond with the two previous studies on feedback-related activity in ADHD. Decreased hippocampal activation in the ADHD group was also observed in the PET-study of Ernst and colleagues (2003). In line with the fMRI-study of Scheres et al. (2007), we also observed reduced ventral striatal activation (nucleus accumbens) in the ADHD group. However, we additionally observed hyporesponsiveness of the dorsal striatum (caudate nucleus) and group differences in activity of the inferior/orbital or middle frontal gyrus. Although, one can argue that part of our results are only marginally significant, it is important to note that in each case the uncorrected $p$-values were smaller than 0.001 and that this value is often used as a statistical threshold (e.g., Durston, Mulder, Casey, Ziermans, \& van Engeland, 2006; Ernst et al., 2003).

Furthermore, a correlation between the amount of inhibition errors made during the Go/NoGo task and the inferior frontal gyri (bilateral) was observed, indicating that an increase in error rate coincided with increased neural activity in these areas. Activity in these frontal gyri is associated with response inhibition, performance monitoring, and error processing (Menon, Adleman, White, Glover, \& Reiss, 2001; Rubia, Smith, Taylor, \& Brammer, 2007). 
$z=-14 \mathrm{~mm}$
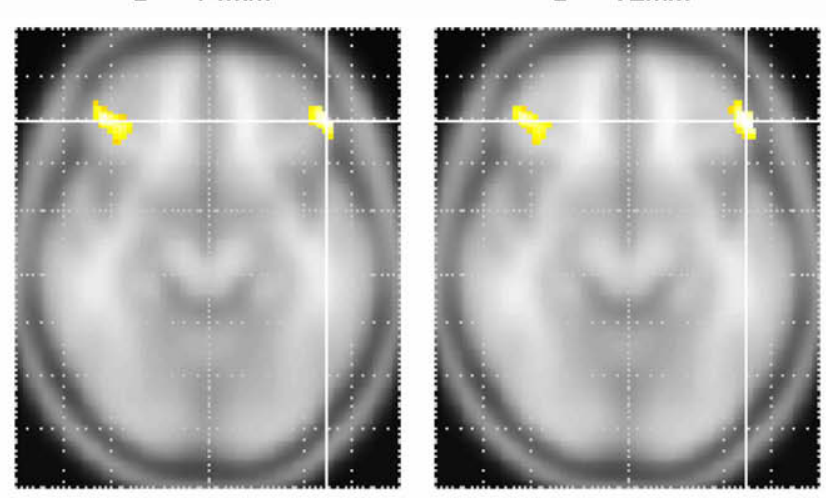

Fitted responses

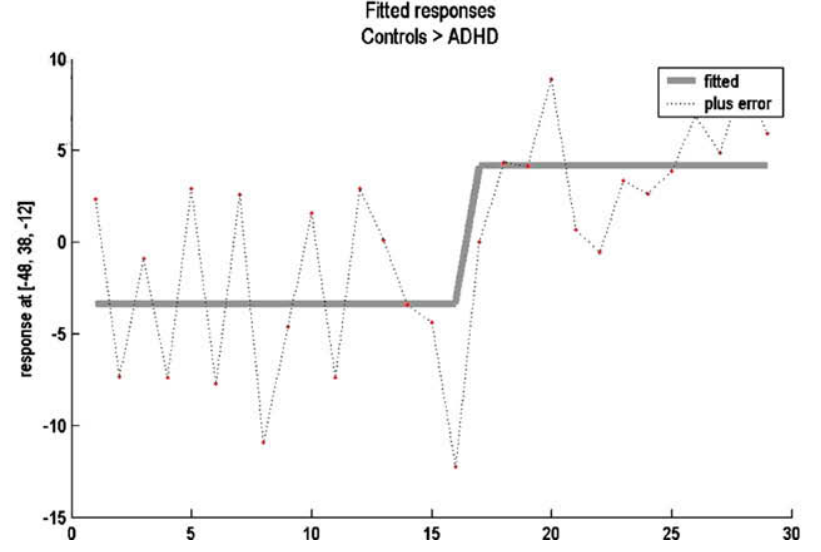

$z=-10 \mathrm{~mm}$

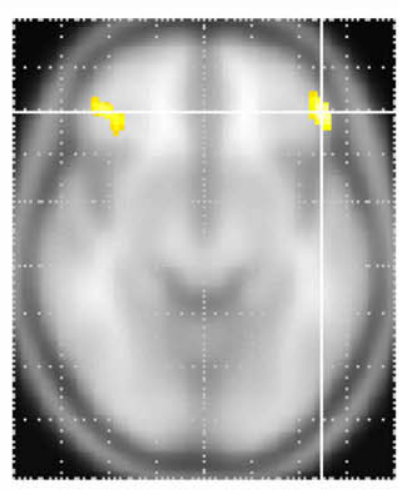

T value

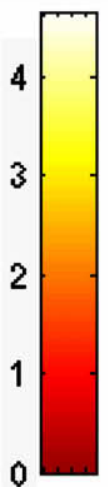

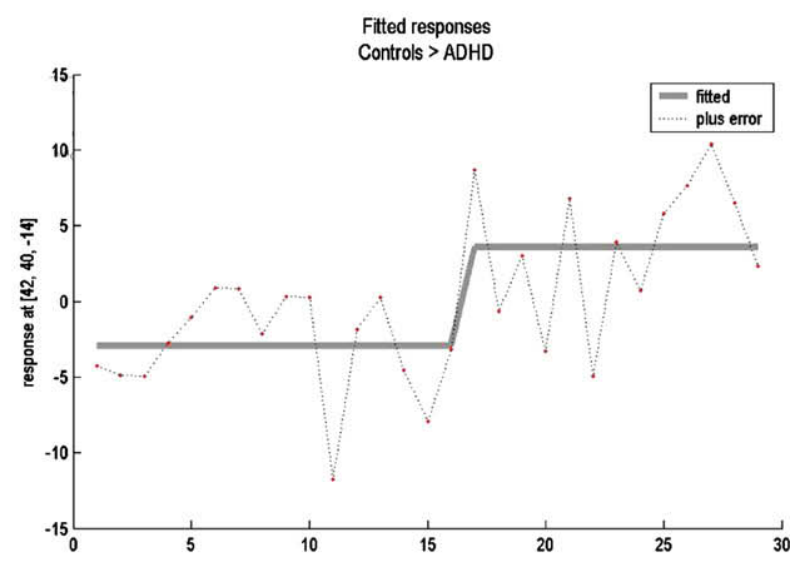

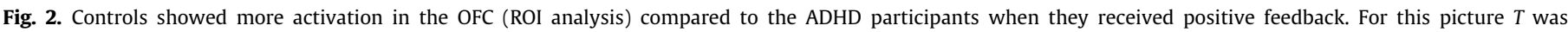

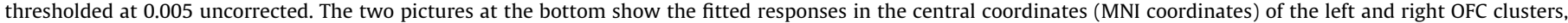
respectively. The numbers on the $x$-axis represent the participants: the numbers 1 until 16 are ADHD adults, the numbers 17-29 are the controls.

Finally, the ADHD group displayed in general more activation in the right middle frontal, part of the dIPFC, gyrus during the Go/ NoGo task (BA9). Such a non-specific hyperactivation of the dlPFC during the performance of a response inhibition task was also observed in children with ADHD (Pliszka et al., 2006). This area is normally associated with executive functions as rule selection, response inhibition, and reward-related processes (Ridderinkhof, van den Wildenberg,et al., 2004). Especially these functions are thought to be impaired in ADHD. It is possible that the ADHD group put more effort in these executive processes in order to perform at the same level as the control participants, resulting in more activity of the right dIPFC.

Taken together, the data correspond to previous studies on response inhibition, feedback, and ADHD. Most importantly, different brain activity was observed for response-inhibition and feedback-related processes and this activity differed between the two groups. Next to specific response- and feedback-related group differences, the ADHD group tended to display more left inferior frontal gyrus/orbitofrontal cortex activity in general. This non-specific increased activity might reflect the exertion of additional energy in order to correctly perform the task (Fassbender \& Schweitzer, 2006). One notable lack of task-related activity is that of the medial surface of the frontal lobe. These medial areas are thought to be strongly involved in cognitive control processes such as performance monitoring, response conflict, and response errors (Ridderinkhof, Ullsperger, Crone, \& Nieuwenhuis, 2004). Especially, on these type of processes taps the current Go/NoGo task. However, separate analysis of the NoGo-Go contrast (correct NoGo trials minus correct Go trials) for each of the groups reveals that the control group did activate these regions. That is, an increase in activity was observed in right medial frontal areas including BA6, 8 , and 9 (whole brain analysis, $T$ s $>4.66, p s<.05$, cluster size 137 , coordinates: 4,39 , and 37 ). No such activity was observed in the ADHD group. This absence or reduction of medial frontal activity has more often been observed in ADHD and is associated with deficits in decision making, response inhibition, and other executive control functions (see for reviews Fassbender \& Schweitzer, 2006; Schneider et al., 2006).

The data are indicative of at least two partly distinctive processes that are altered in ADHD. This notion concords with models that comprehend both executive and reward/motivation dysfunction in ADHD. One such model is the dual pathway model of Sonuga-Barke (2003). In this model disturbances in the fronto-dorsal striatal circuit are associated with executive dysfunction, whereas altered reward processes are linked to the fronto-ventral circuit. Each circuit is influenced by an input from different branches of the dopamine system. Especially, this modulator dopamine is known to be affected in ADHD. The group differences observed in the present experiment partly concord with the dual pathway model. At a behavioral level, the difference between the ADHD and control group was most pronounced in the executive circuit. The group adults with ADHD displayed more attention problems and a tendency towards larger response inhibition problems, both associated with executive dysfunction, than did the control group. At a neuronal level, aberrant activity was found in the putamen, part of the executive circuit, during NoGo trials. Deficits in the reward/motivation circuit were observed in the OFC and hippocampus/nucleus accumbens. Contrary to the expectations of the model, 
$z=-26 \mathrm{~mm}$

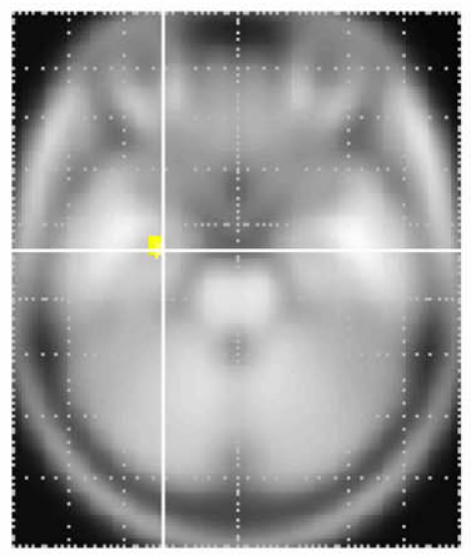

$z=-24 m m$

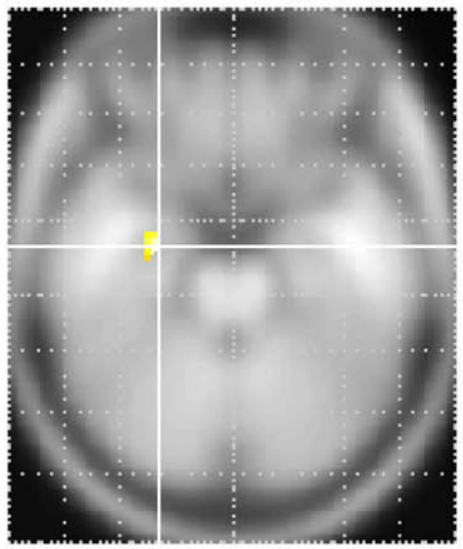

$z=-22 m m$

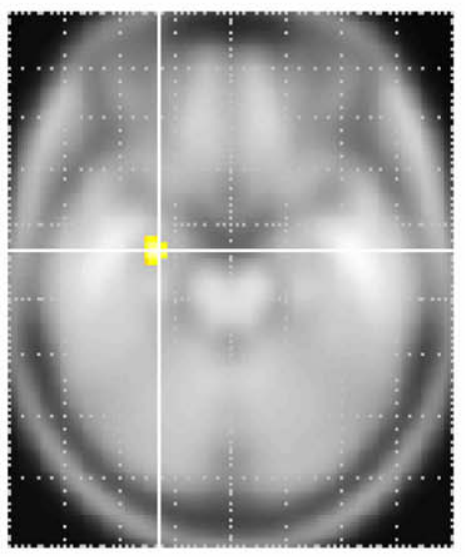

T value

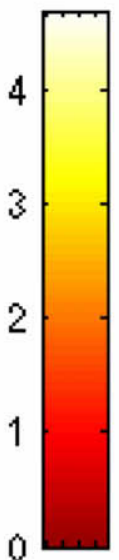

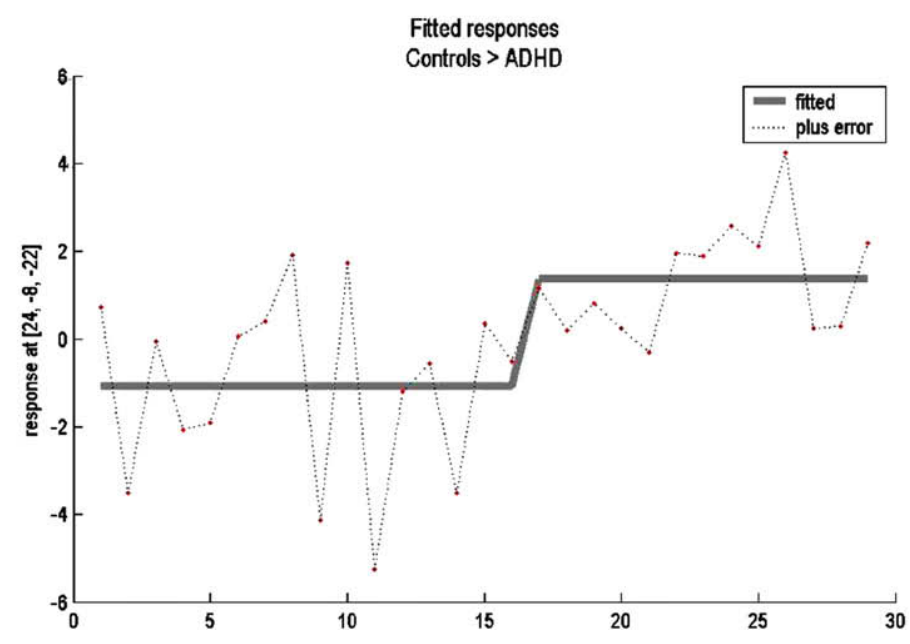

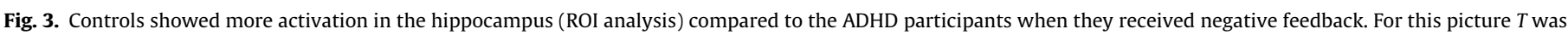

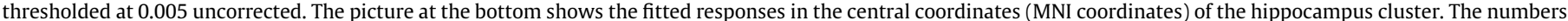
on the $x$-axis represent the participants: the numbers 1 until 16 are ADHD adults, the numbers 17-29 are the controls.

\section{Table 5}

Brain activation during response inhibition (NoGo-Go) that correlates positively with the total number of inhibition errors made during the Go/NoGo task (whole brain analysis).

\begin{tabular}{lllllr}
\hline TAL & $\begin{array}{l}\text { Cluster } \\
\text { size }\end{array}$ & $\begin{array}{l}T- \\
\text { value }\end{array}$ & $P_{\text {corrected_cluster }}$ & Brain region & BA \\
\hline$[-53,35,-7]$ & 332 & 6.93 & 0.001 & $\begin{array}{l}\text { Inferior frontal } \\
\text { gyrus/ }\end{array}$ & 47 \\
{$[-57,16,3]$} & & 4.82 & & $\begin{array}{l}\text { Orbitofrontal cortex } \\
\text { Inferior frontal }\end{array}$ & 45 \\
{$[55,27,-1]$} & 309 & 5.32 & 0.002 & $\begin{array}{l}\text { gyrus/ } \\
\text { Orbitofrontal cortex }\end{array}$ & 44 \\
{$[51,14,10]$} & & 4.92 & & & 46 \\
{$[51,33,8]$} & & 4.17 & & & \\
\hline
\end{tabular}

atypical caudate and OFC activity was also observed during positive feedback and Go/NoGo trials, respectively. As mentioned before, one can argue that the relative increase in OFC activity in the ADHD group is linked to additional effort and therefore, taps on motivational processes. The hypoactivation of the caudate nucleus during feedback-related processes was unexpected. According the dual pathway model activation of the caudate nucleus is associated with the executive circuit and not directly linked to the reward/motivation system. However, several other studies do find a relation between activity of the caudate nucleus and feedback-related processes such as the association between a stimulus, response, and outcome (e.g., Haruno \& Kawato, 2006a, 2006b; O’Doherty et al., 2004; Tricomi, Delgado, \& Fiez, 2004). This does not imply that the model is incorrect, but further research can help to clarify the role of the caudate nucleus in the executive control and reward/motivation circuits.

There are limitations in the present study that need to be acknowledged. First, we only looked at feedback-related processes and not at reward or punishment. The colored blocks, red for incorrect trials and green for correct trials, provided performance feedback, but are not necessary punishing or reinforcing. Although, we did observe adjusted responding after an omitted Go trial with negative feedback, it would also be interesting to use a stronger incentive/punisher, such as monetary response feedback in a future experiment. This might enhance the power to observe group differences in the negative-positive feedback contrast. Second, as mentioned above, feedback did influence performance on subsequent trials. Therefore, in the current experiment feedback- and inhibition-related processes are not entirely independent. This problem could be solved by doubling the number of Go and NoGo trials and providing feedback on only half of these trials. Inhibition-related processes could be analyzed by including only Go and NoGo trials that follow non-feedback trials. Feedback could be examined by investigating correct and incorrect trials provided with feedback, like in the present study. This design additionally creates the opportunity to further examine performance monitor- 
$z=-2 m m$

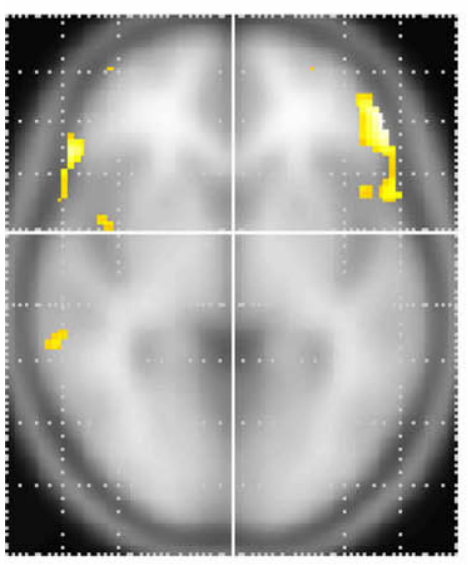

$z=0 \mathrm{~mm}$

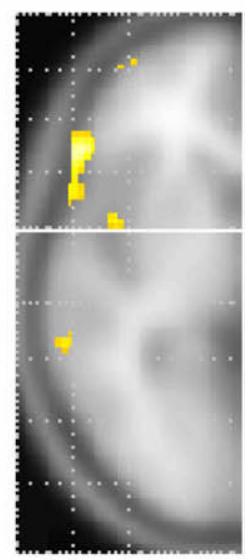

$z=2 \mathrm{~mm}$

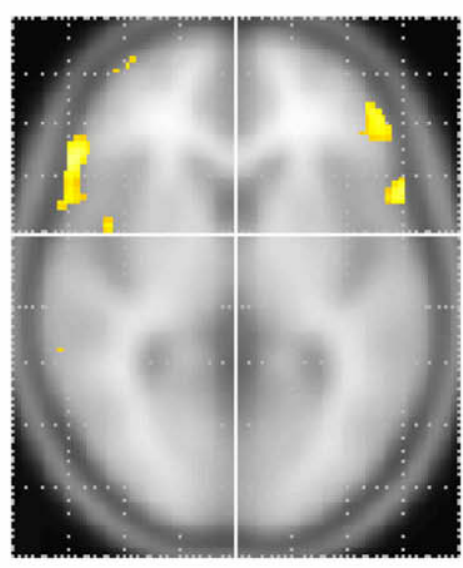

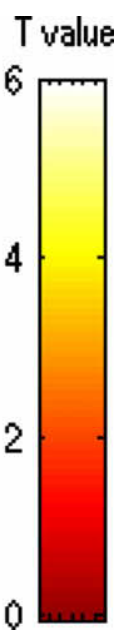

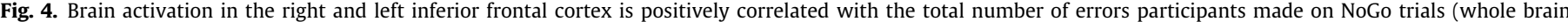
analysis). For this picture $T$ was thresholded at 0.001 uncorrected.

ing processes by analyzing Go/NoGo trials that succeed feedback trials.

Although the task obviously also taps on other cognitive processes such as attention and memory, we do think that the modified version of the Go/NoGo task is a useful tool to further examine feedback- and inhibition-related neural activity. Third, we can not exclude the possibility that some of the participants had comorbid disorders. Even though none of the participants reported to have been diagnosed with another axis I or II disorder, some did report additional symptoms of depression, obsessive/compulsive behavior, or learning problems. These additional problems might have obscured the results. In future experiments additional neuropsychological tests or interviews, such as a SCID (Dutch version: Groenestijn, Akkerhuis, Kupka, Schneider, \& Nolen, 1997), should be incorporated before onset of the experiment to exclude or identify these problems. It would also be interesting to include two adult ADHD groups, one with comorbid disorders and one without. Comparing these groups to a healthy control group and each other can help to provide more insight in the neural and behavioral processes that are specifically related to ADHD and to ADHD plus comorbid problems. Finally, although the participants refrained from any ADHD medication at least $24 \mathrm{~h}$ prior to scanning, most were not medication naïve. Therefore, it remains possible that the observed brain activity differences were due to (long-term) effects of the stimulant medication. A longer wash-out period or including only medication naïve participants would solve this problem (but see Pliszka, 2007).

\section{Conclusion}

The present study shows that adults with ADHD have more activation in the inferior frontal gyrus and putamen during response inhibition than healthy controls. This pattern differs from the feedback-related activation in which ADHD adults displayed more activity in the inferior frontal gyrus and less activity in the inferior frontal/orbitofrontal cortex, hippocampus/nucleus accumbens, and caudate nucleus. These results largely concord with previous experiments and support a dual pathway model in which distinctive brain structures are involved for response inhibition, or more general executive control, and motivation/reward. Both the model and the present study indicate that ADHD-problems are related to both executive dysfunction and motivation/reward alterations. Such a separation in distinct dysfunctions can help to further develop new treatments and diagnostic tools for ADHD.

\section{Acknowledgments}

The authors acknowledge Katja Bakker for her effort to recruit and test all participants. We also like to thank Etienne Lemaire, Walter Backes, and all other radiology employees for their helpful comments on our fMRI protocol and their time to scan all participants.

\section{References}

Antrop, I., Stock, P., Verte, S., Wiersema, J. R., Baeyens, D., \& Roeyers, H. (2006) ADHD and delay aversion: The influence of non-temporal stimulation on choice for delayed rewards. Journal of Child Psychology and Psychiatry, 47(11), $1152-1158$.

APA (2000). Diagnostic and statistical manual of mental disorders (4th ed.) Washington, DC: American Psychiatric Association.

Barkley, R. A. (1997). Behavioral inhibition, sustained attention, and executive functions: Constructing a unifying theory of ADHD. Psychological Bulletin, 121(1), 65-94.

Barkley, R. A. (2000). Genetics of childhood disorders: XVII. ADHD, Part 1: The executive functions and ADHD. Journal of the American Academy of Child and Adolescent Psychiatry, 39(8), 1064-1068.

Barkley, R.A., \& Murphy, K.R. (1998). Attention-deficit hyperactivity disorder: A clinical workbook (2nd ed.)

Braaten, E. B., \& Rosen, L. A. (1997). Emotional reactions in adults with symptoms of attention deficit hyperactivity disorder. Personality and Individual Differences, 22(3), 355-361.

Bridgett, D. J., \& Walker, M. E. (2006). Intellectual functioning in adults with ADHD: A meta-analytic examination of full scale IQ differences between adults with and without ADHD. Psychological Assessment, 18(1), 1-14.

Bush, G., Frazier, J. A., Rauch, S. L., Seidman, L. J., Whalen, P. J., Jenike, M. A., et al (1999). Anterior cingulate cortex dysfunction in attention-deficit/hyperactivity disorder revealed by fMRI and the counting stroop. Biological Psychiatry, 45(12), 1542-1552.

Bush, G., Valera, E. M., \& Seidman, L. J. (2005). Functional neuroimaging of attentiondeficit/hyperactivity disorder: A review and suggested future directions. Biological Psychiatry, 57(11), 1273-1284.

Cao, Q., Zang, Y., Zhu, C., Cao, X., Sun, L., Zhou, X., et al. (2008). Alerting deficits in children with attention deficit/hyperactivity disorder: Event-related fMRI evidence. Brain Research, 1219, 159-168.

Chevrier, A. D., Noseworthy, M. D., \& Schachar, R. (2007). Dissociation of response inhibition and performance monitoring in the stop signal task using eventrelated fMRI. Human Brain Mapping, 28(12), 1347-1358.

De Bie, S. E. (1987). Standaardvragen 1987: Voorstellen voor uniformering van vraagstellingen naar achtergrondkenmerken en interviews [Standard questions 1987: Proposal for uniformization of questions regarding background variables and interviews] (2nd ed.). Leiden, The Netherlands: Leiden University Press.

Douglas, V. I., \& Parry, P. A. (1994). Effects of reward and nonreward on frustration and attention in attention deficit disorder. Journal of Abnormal Child Psychology, 22(3), 281-302.

Durston, S. (2003). A review of the biological bases of ADHD: What have we learned from imaging studies? Mental Retardation and Developmental Disabilities Research Reviews, 9(3), 184-195.

Durston, S., Mulder, M., Casey, B. J., Ziermans, T., \& van Engeland, H. (2006) Activation in ventral prefrontal cortex is sensitive to genetic vulnerability for 
attention-deficit hyperactivity disorder. Biological Psychiatry, 60(10), 1062-1070.

Elliott, R., Friston, K. J., \& Dolan, R. J. (2000). Dissociable neural responses in human reward systems. Journal of Neuroscience, 20(16), 6159-6165.

Ernst, M., Kimes, A. S., London, E. D., Matochik, J. A., Eldreth, D., Tata, S., et al. (2003) Neural substrates of decision making in adults with attention deficit hyperactivity disorder. American Journal of Psychiatry, 160(6), 1061-1070.

Evers, E. A., van der Veen, F. M., van Deursen, J. A., Schmitt, J. A., Deutz, N. E., \& Jolles, J. (2006). The effect of acute tryptophan depletion on the BOLD response during performance monitoring and response inhibition in healthy male volunteers. Psychopharmacology (Berl), 187(2), 200-208.

Fassbender, C. \& Schweitzer, J. B. (2006). Is there evidence for neural compensation in attention deficit hyperactivity disorder? A review of the functional neuroimaging literature. Clinical Psychological Review, 26(4), 445-465.

Garavan, H., Ross, T. J., \& Stein, E. A. (1999). Right hemispheric dominance of inhibitory control: An event-related functional MRI study. Proceedings of the National Academy of Sciences of the United States of America, 96(14), 8301-8306.

Gomez, R. (2003). Underlying processes in the poor response inhibition of children with attention-deficit/hyperactivity disorder. Journal of Attention Disorders, 6(3), $111-122$

Groenestijn, M. A. C., Akkerhuis, G. W., Kupka, R. W., Schneider, H., \& Nolen, W. A (1997). Gestructureerd Klinisch Interview voor de Vaststelling van DSM-IV As I Stoornissen, Nederlandse vertaling, SCID-I. Lisse: Swets \& Zeitlinger.

Haenlein, M., \& Caul, W. F. (1987). Attention deficit disorder with hyperactivity: A specific hypothesis of reward dysfunction. Journal of the American Academy of Child and Adolescent Psychiatry, 26(3), 356-362.

Haruno, M., \& Kawato, M. (2006a). Different neural correlates of reward expectation and reward expectation error in the putamen and caudate nucleus during stimulus-action-reward association learning. Journal of Neurophysiology, 95(2), 948-959.

Haruno, M., \& Kawato, M. (2006b). Heterarchical reinforcement-learning model for integration of multiple cortico-striatal loops: fMRI examination in stimulusaction-reward association learning. Neural Networks, 19(8), 1242-1254.

Hervey, A. S., Epstein, J. N., \& Curry, J. F. (2004). Neuropsychology of adults with attention-deficit/hyperactivity disorder: A meta-analytic review. Neuropsychology, 18(3), 485-503.

Kaufman, A.S., \& Lichtenberger, E.O. (1999). Essentials of WAIS-III assessment.

Knutson, B., Adams, C. M., Fong, G. W., \& Hommer, D. (2001). Anticipation of increasing monetary reward selectively recruits nucleus accumbens. Journal of Neuroscience, 21(16), RC159.

Konrad, K., Neufang, S., Hanisch, C., Fink, G. R., \& Herpertz-Dahlmann, B. (2006). Dysfunctional attentional networks in children with attention deficit/ hyperactivity disorder: Evidence from an event-related functional magnetic resonance imaging study. Biological Psychiatry, 59(7), 643-651.

Luman, M., Oosterlaan, J., \& Sergeant, J. A. (2005). The impact of reinforcement contingencies on AD/HD: A review and theoretical appraisal. Clinical Psychology Review, 25(2), 183-213.

Menon, V., Adleman, N. E., White, C. D., Glover, G. H., \& Reiss, A. L. (2001). Errorrelated brain activation during a Go/NoGo response inhibition task. Human Brain Mapping, 12(3), 131-143.

O’Doherty, J., Dayan, P., Schultz, J., Deichmann, R., Friston, K., \& Dolan, R. J. (2004) Dissociable roles of ventral and dorsal striatum in instrumental conditioning. Science, 304(5669), 452-454.

Pliszka, S. R. (2007). Pharmacologic treatment of attention-deficit/hyperactivity disorder: Efficacy, safety and mechanisms of action. Neuropsychology Review, 17(1), 61-72

Pliszka, S. R., Glahn, D. C., Semrud-Clikeman, M., Franklin, C., Perez, R., 3rd, Xiong, J. et al. (2006). Neuroimaging of inhibitory control areas in children with attention deficit hyperactivity disorder who were treatment naive or in longterm treatment. American Journal of Psychiatry, 163(6), 1052-1060.

Ridderinkhof, K. R., Ullsperger, M., Crone, E. A., \& Nieuwenhuis, S. (2004). The role of the medial frontal cortex in cognitive control. Science, 306(5695), 443-447.

Ridderinkhof, K. R., van den Wildenberg, W. P., Segalowitz, S. J., \& Carter, C. S (2004). Neurocognitive mechanisms of cognitive control: The role of prefrontal cortex in action selection, response inhibition, performance monitoring, and reward-based learning. Brain and Cognition, 56(2), 129-140.

Rubia, K., Russell, T., Overmeyer, S., Brammer, M. J., Bullmore, E. T., Sharma, T., et al (2001). Mapping motor inhibition: Conjunctive brain activations across different versions of go/no-go and stop tasks. Neuroimage, 13(2), 250-261.
Rubia, K., Smith, A. B., Taylor, E., \& Brammer, M. (2007). Linear age-correlated functional development of right inferior fronto-striato-cerebellar networks during response inhibition and anterior cingulate during error-related processes. Human Brain Mapping, 28(11), 1163-1177.

Sagvolden, T., Aase, H., Johansen, E. B., \& Russell, V. A. (2005). A dynamic developmental theory of attention-deficit/hyperactivity disorder (ADHD) predominantly hyperactive/impulsive and combined subtypes. Behavioral and Brain Sciences, 28(3), 397-468.

Scheres, A., Milham, M. P., Knutson, B., \& Castellanos, F. X. (2007). Ventral striatal hyporesponsiveness during reward anticipation in attention-deficit/ hyperactivity disorder. Biological Psychiatry, 61(5), 720-724.

Schneider, M., Retz, W., Coogan, A., Thome, J., \& Rosler, M. (2006). Anatomical and functional brain imaging in adult attention-deficit/hyperactivity disorder (ADHD)-A neurological view. European Archives of Psychiatry and Clinical Neuroscience, 256(1), i32-i41.

Schulz, K. P., Fan, J., Tang, C. Y., Newcorn, J. H., Buchsbaum, M. S., Cheung, A. M., et al. (2004). Response inhibition in adolescents diagnosed with attention deficit hyperactivity disorder during childhood: An event-related fMRI study. American Journal of Psychiatry, 161(9), 1650-1657.

Seidman, L. J., Biederman, J., Weber, W., Hatch, M., \& Faraone, S. V. (1998). Neuropsychological function in adults with attention-deficit hyperactivity disorder. Biological Psychiatry, 44(4), 260-268.

Sergeant, J. A., Geurts, H., Huijbregts, S., Scheres, A., \& Oosterlaan, J. (2003). The top and the bottom of ADHD: A neuropsychological perspective. Neuroscience and Biobehavioral Reviews, 27(7), 583-592.

Simmonds, D. J., Pekar, J. J., \& Mostofsky, S. H. (2008). Meta-analysis of Go/No-go tasks demonstrating that fMRI activation associated with response inhibition is task-dependent. Neuropsychologia, 46(1), 224-232.

Sonuga-Barke, E. J. (2003). The dual pathway model of AD/HD: An elaboration of neuro-developmental characteristics. Neuroscience and Biobehavioral Reviews, 27(7), 593-604

Stevens, M. C., Kiehl, K. A., Pearlson, G. D., \& Calhoun, V. D. (2007). Brain network dynamics during error commission. Human Brain Mapping.

Talairach, J., \& Tournoux, P. (1988). Co-planar stereotaxic atlas of the human brain. New York: Thieme.

Tamm, L., Menon, V., Ringel, J., \& Reiss, A. L. (2004). Event-related fMRI evidence of frontotemporal involvement in aberrant response inhibition and task switching in attention-deficit/hyperactivity disorder. Journal of the American Academy of Child and Adolescent Psychiatry, 43(11), 1430-1440.

Tricomi, E. M., Delgado, M. R., \& Fiez, J. A. (2004). Modulation of caudate activity by action contingency. Neuron, 41(2), 281-292.

Tzourio-Mazoyer, N., Landeau, B., Papathanassiou, D., Crivello, F., Etard, O., Delcroix, N., et al. (2002). Automated anatomical labeling of activations in SPM using a macroscopic anatomical parcellation of the MNI MRI single-subject brain. Neuroimage, 15(1), 273-289.

Uterwijk, J. (2000). WAIS-III Nederlandstalige bewerking. Technische handleiding. Lisse: Swets \& Zeitlinger.

Vaidya, C. J., Austin, G., Kirkorian, G., Ridlehuber, H. W., Desmond, J. E., Glover, G. H., et al. (1998). Selective effects of methylphenidate in attention deficit hyperactivity disorder: A functional magnetic resonance study. Proceedings of the National Academy of Sciences of the United States of America, 95(24), 14494-14499.

van Leijenhorst, L., Crone, E. A., \& Bunge, S. A. (2006). Neural correlates of developmental differences in risk estimation and feedback processing. Neuropsychologia, 44(11), 2158-2170.

van Meel, C. S., Oosterlaan, J., Heslenfeld, D. J., \& Sergeant, J. A. (2005). Telling good from bad news: ADHD differentially affects processing of positive and negative feedback during guessing. Neuropsychologia, 43(13), 1946-1954.

Willcutt, E. G., Doyle, A. E., Nigg, J. T., Faraone, S. V., \& Pennington, B. F. (2005). Validity of the executive function theory of attention-deficit/hyperactivity disorder: A meta-analytic review. Biological Psychiatry, 57(11), 1336-1346.

Zalla, T., Koechlin, E., Pietrini, P., Basso, G., Aquino, P., Sirigu, A., et al. (2000). Differential amygdala responses to winning and losing: A functional magnetic resonance imaging study in humans. European Journal of Neuroscience, 12(5), 1764-1770.

Zanolie, K., Van Leijenhorst, L., Rombouts, S. A., \& Crone, E. A. (2008). Separable neural mechanisms contribute to feedback processing in a rule-learning task. Neuropsychologia, 46(1), 117-126. 